\title{
Avaliação da não completude das notificações compulsórias de dengue registradas por município de pequeno porte no Brasil
}

\author{
Assessment of the lack of completeness of compulsory dengue fever \\ notifications registered by a small municipality in Brazil
}

Carla Adriana Marques (https://orcid.org/0000-0002-3977-8034) ${ }^{1}$

Marluce Mechelli de Siqueira (https://orcid.org/0000-0002-6706-5015) ${ }^{2}$

Flávia Batista Portugal (https://orcid.org/0000-0002-4425-2627) ${ }^{2}$

${ }^{1}$ Programa de PósGraduação em Enfermagem, Universidade Federal do Espírito Santo. Av. Marechal Campos 1468, Bonfim. 29047-105 Vitória ES Brasil.carlaadriana25@ hotmail.com

${ }^{2}$ Departamento de Enfermagem, Universidade Federal do Espírito Santo.

Vitória ES Brasil.

\begin{abstract}
This article aims to analyze the completeness of the dengue fever notifications registered in a small municipality in Brazil, from 2007 to 2015. It involved a descriptive study with a quantitative approach, composed of the totality of records available in the National System of Notifiable Diseases. The absolute number and percentage of non-fulfilment of the key, mandatory and essential variables of the dengue notification forms were analyzed, and a score proposed by Romero $e$ Cunha was used to assess the degree of non-completeness. The non-parametric linear correlation coefficient of Spearman ( $r s$ ) was calculated, being preceded by the verification of the distribution of the data through the Kolmogorov Smirnov test. The proportion of information ignored was high for most of the variables and for some trends of non-completeness over the years were decreasing and statistically significant. The quality of the data was mostly classified as regular and very poor, making it imperative to establish strategies in the process of qualification of health teams that work in primary care, to raise awareness of the importance of quality in the registration of compulsory notifications.
\end{abstract}

Key words Dengue fever, Epidemiological surveillance, Compulsory notification, Health information system
Resumo $O$ objetivo deste artigo é analisar a completude dos campos de notificações de dengue registradas em um município de pequeno porte no Brasil, no período de 2007 a 2015. Estudo descritivo com abordagem quantitativa, composto pela totalidade de registros disponiveis no Sistema Nacional de Agravos de Notificação. Analisou-se o número absoluto e o percentual de não preenchimento das variáveis chave, obrigatórias e essenciais das fichas de notificação de dengue e com a finalidade de avaliar os graus de não completude, adotou-se escore proposto por Romero e Cunha. Foi calculado o coeficiente não paramétrico de correlação linear de Spearman ( $r s)$, sendo precedido pela verificação da distribuição dos dados através do teste de Kolmogorov Smirnov. A proporção de informações ignoradas foi elevada para a maioria das variáveis e para algumas, as tendências de não completude no decorrer dos anos foram decrescentes e estatisticamente significantes. A qualidade dos dados foi, em sua maioria, classificada como regular e muito ruim, tornando-se imprescindivel o estabelecimento de estratégias no processo de capacitação das equipes de saúde que atuam na atenção primária, para a sensibilização e conscientização da importância da qualidade no registro das notificações compulsórias.

Palavras-chave Dengue, Vigilância epidemiológica, Notificação compulsória, Sistema de Informação em Saúde 


\section{Introdução}

A dengue é considerada pela Organização Mundial de Saúde (OMS) um dos mais sérios problemas de saúde pública do mundoํ. Ela é uma doença febril aguda, de etiologia viral e que se manifesta de formas variadas, desde uma forma assintomática até quadros graves e hemorrágicos, podendo levar ao óbito ${ }^{2,3}$. O principal transmissor da dengue é o mosquito A. aegypti e a sua disseminação acontece especialmente nos países tropicais e subtropicais, onde as condições do meio ambiente favorecem a proliferação dos vetores ${ }^{1}$.

Foram registrados no Brasil no ano de 2015 e 2016, respectivamente, 1.688 .688 e 1.500 .535 casos prováveis de dengue ${ }^{4}$. Diversos fatores são condicionantes da expansão da dengue no Brasil e no mundo, como por exemplo, o crescimento desordenado das cidades com importantes lacunas no setor de infraestrutura, a rápida urbanização, a falta de saneamento básico, o aumento da circulação de pessoas, a existência de vários sorotipos distintos, as condições climáticas favoráveis e o difícil controle do vetor. Esta realidade tem colocado cerca de metade da população mundial sob risco nos dias atuais, caracterizando a doença como uma pandemia ${ }^{5,6}$.

O controle da doença tem sido uma atividade complexa, principalmente pela rápida transmissão vetorial e o aumento da sua ocorrência, principalmente dos casos graves de dengue, tem se constituído um crescente objeto de preocupação para a sociedade, e em especial, para as autoridades de saúde 7 .

Neste contexto, a dengue é uma das doenças de notificação compulsória, devendo todo caso suspeito ou confirmado ser notificado ao Serviço de Vigilância Epidemiológica ${ }^{8}$, para que, por meio dos dados notificados, possa-se adotar medidas de bloqueio adequadas e capazes de reduzir a circulação viral e, consequentemente, a redução do número de casos ${ }^{1,9}$.

Essas notificações alimentam o Sistema de Informação de Agravos de Notificação (SINAN), o qual constitui-se a principal fonte de informação para o estudo da história natural de um agravo ou doenç ${ }^{10}$. As informações obtidas a partir das notificações possibilitam o monitoramento espaço-temporal de epidemias no país, subsidiando as ações para sua prevenção e controle. Portanto, para que o serviço da Vigilância seja eficiente, é necessário, que essas informações sejam de boa qualidade $^{8}$.

O mau preenchimento das fichas de notificação favorece a geração de dados deficientes e não confiáveis, o que contribui para o desconhecimento do processo de saúde-doença ${ }^{11}$. Para tanto, é necessário que esses dados sejam avaliados e para tal, é indicada a análise da qualidade da base de dados do SINAN quanto à completude dos campos. O termo completude refere-se ao grau de preenchimento de campo analisado, mensurado pela proporção de notificações com campo preenchido com categoria distinta daquelas indicadoras de ausência do dado ${ }^{12}$.

Frente ao exposto, este trabalho visa analisar a qualidade dos dados das notificações de dengue quanto ao aspecto de completude dos campos, de residentes do município de Fundão, Espírito Santo, registradas no SINAN, no período de 2007 a 2015.

\section{Método}

Trata-se de um estudo descritivo e de abordagem quantitativa, realizado a partir de dados disponíveis no SINAN. Foram utilizadas como unidades de análise, as notificações de dengue de residentes no município de Fundão, Espírito Santo, realizadas no período de 2007 a 2015.

Fundão é um município de pequeno porte pertencente à Região Metropolitana da Grande Vitória ${ }^{13}$ e sua população foi estimada, no ano de 2016, em 20.376 habitantes, sendo considerado um município de pequeno porte, segundo o IBGE ${ }^{14}$. Com uma taxa de urbanização da ordem de $84 \%$ e uma média de $80 \%$ de cobertura da Estratégia Saúde da Família, o município conta com cinco estabelecimentos de saúde, sendo quatro Unidades Básicas de Saúde e um Pronto Atendimento Municipal ${ }^{13}$.

As notificações utilizadas neste estudo foram disponibilizadas pelo serviço de Vigilância Epidemiológica, mediante autorização dada pela Secretaria Municipal de Saúde. Foram incluídos no estudo, todos os casos suspeitos e confirmados da doença, inseridos no SINAN, durante o período supracitado, sendo excluídos os casos duplicados. As duplicidades foram identificadas a partir da análise de registros organizados pela data de notificação, comparando-se os nomes do paciente e da mãe, data de nascimento e data de início dos primeiros sintomas.

Selecionou-se o supracitado período, pois o ano de 2007 iniciou-se a operacionalização do SINAN NET no município, a partir do qual os dados de dengue começaram a ser inseridos. Em 2014, com a atualização do SINAN, o banco de dados de dengue no SINAN NET migrou para o 
banco de dados do SINAN dengue online. Todo o banco de dados em análise neste estudo foi exportado da versão 3.0 do SINAN dengue online, por meio de arquivos em DBF. Assim, foi realizada a manipulação de apenas um banco de dados durante o desenvolvimento do estudo.

Foram selecionadas para análise as variáveis com campos-chave, campos obrigatórios e campos essenciais das fichas de notificação e investigação de dengue, segundo sua importância epidemiológica. Conforme o roteiro para uso de SINAN NET, o campo-chave corresponde aos identificadores do registro no sistema, o campo de preenchimento obrigatório é aquele cuja ausência do dado impossibilita a inclusão da notificação ou da investigação no SINAN e campo essencial é aquele que, apesar de não ser obrigatório, registra dados importantes e necessários à investigação do caso notificado ${ }^{15}$. Para avaliação da completude, os campos preenchidos no banco de dados com categoria "Ignorado", numeral zero, data ignorada ou termo que indica ausência do dado também serão considerados incompletos ${ }^{12}$.

Desta forma, são considerados campos-chave da ficha de notificação de dengue, o número da notificação, agravo, data da notificação e $m u$ nicípio de notificação. As variáveis obrigatórias estudadas quanto à completude foram: data dos primeiros sintomas, nome completo do paciente, idade, sexo, data de nascimento, gestante, município de residência, data da investigação, sorotipo, classificação final, critério de confirmação/descarte e caso autóctone do município de residência. As variáveis essenciais estudadas quanto ao mesmo atributo foram: raça/cor, escolaridade, número do cartão do SUS, nome da mãe, nome do bairro, número de telefone, zona, ocupação/ramo de atividade econômica, resultado do exame sorológico - IgM, resultado de isolamento viral, resultado do exame RT/PCR, resultado da histopatologia, resultado da imunohistoquímica, provável município de infecção, evolução do caso, data de encerramento e se ocorreu hospitalização. Estas variáveis foram organizadas em blocos de localização nas fichas: Dados Gerais, Dados Individuais, Dados de Residência, Dados Laboratoriais e Dados da Conclusão.

Para a avaliação da não completude dos dados, utilizou-se o sistema de escores proposto por Romero e Cunha ${ }^{16}$, com os seguintes graus de avaliação: excelente (não completude menor de 5\%); bom (não completude de 5 a 10\%); regular (não completude de 10 a 20\%); ruim (não completude de 20 a 50\%) e muito ruim (não completude de $50 \%$ ou mais).
Quanto à análise dos dados, utilizou-se o programa estatístico SPSS Statistics versão 22. Os dados foram analisados de forma descritiva, por meio de porcentagens, bem como foi calculado o coeficiente não paramétrico de correlação linear de Spearman ( $r$ ) , seu valor de p e a representação de suas completudes ao longo do tempo (2007 a 2015). O uso do coeficiente não paramétrico foi precedido pela verificação da distribuição dos dados utilizando o teste de Kolmogorov Smirnov.

Destaca-se que todo o processo de pesquisa foi conduzido conforme a Resolução no 466/12 do Conselho Nacional de Saúde (CNS), tendo sido aprovado pelo Comitê de Ética e Pesquisa do Centro de Ciências da Saúde da Universidade Federal do Espírito Santo.

\section{Resultados}

A análise das fichas de notificações de dengue inseridas no SINAN no período compreendido entre 2007 a 2015 no município de Fundão-ES permitiu identificar a ocorrência de 725 notificações realizadas do referido agravo, de residentes do município. Dessas 725 notificações, 10 fichas foram identificadas como duplicidade e foram removidas, por critério de exclusão, totalizando uma amostra de 715 fichas de notificação/investigação de dengue.

Nesse período, o ano de 2008 foi o que apresentou menor número de casos $(\mathrm{n}=14)$, consequentemente, apresentou a menor incidência também $(86,8)$. Já o ano de 2011 foi o com maior número de casos, com 212 notificações realizadas, sendo a incidência de 1.223 por 100.000 habitantes (Tabela 1).

$\mathrm{Na}$ Tabela 2, observa-se a análise de completude dos dados. A completude dos campos-chave (número da notificação, agravo, data da notificação e município de notificação) tiveram 100\% de preenchimento. Ainda nessa categoria, as variáveis obrigatórias nome completo do paciente, data dos primeiros sintomas, idade, sexo e município de residência também atenderam aos 100\% de preenchimento em todos os anos analisados, sendo classificadas como excelente, em escore de completude.

Por outro lado, para os campos obrigatórios, observou-se que em alguns deles ocorreram preenchimento abaixo de $100 \%$, como o percentual de dados ignorados nas variáveis data e nascimento (1\%), data da investigação (6\%), gestante (7,3\%), classificação final (10,8\%), critério de confirmação/descarte (11,6\%), caso autóctone do município de residência (78,7\%) e sorotipo (98,7\%). 
Tabela 1. Incidência e distribuição das notificações sobre Dengue no SINAN. Fundão, Espírito Santo, 2007-2015.

\begin{tabular}{lrrrrrrrrr}
\hline \multicolumn{1}{c}{ Ano } & $\mathbf{2 0 0 7}$ & $\mathbf{2 0 0 8}$ & $\mathbf{2 0 0 9}$ & $\mathbf{2 0 1 0}$ & $\mathbf{2 0 1 1}$ & $\mathbf{2 0 1 2}$ & $\mathbf{2 0 1 3}$ & $\mathbf{2 0 1 4}$ & $\mathbf{2 0 1 5}$ \\
\hline Casos & 49 & 14 & 31 & 22 & 212 & 63 & 172 & 33 & 119 \\
População & 15.209 & 16.125 & 16.431 & 17.028 & 17.334 & 17.632 & 19.177 & 19.585 & 19.985 \\
Incidência/100.000 habitantes & 322,2 & 86,8 & 188,7 & 129,2 & 1223,0 & 357,3 & 896,9 & 168,5 & 595,4 \\
\hline
\end{tabular}

Tabela 2. Classificação, preenchimento e qualidade de campos das fichas de notificação e investigação de dengue no SINAN. Fundão, Espírito Santo, 2007-2015.

\begin{tabular}{|c|c|c|c|c|}
\hline Campo/Variável & $\begin{array}{l}\text { Classificação } \\
\text { do Campo }\end{array}$ & $\begin{array}{c}\text { Preenchimento } \\
\%\end{array}$ & $\begin{array}{c}\text { Informação } \\
\text { Ignorada ou } \\
\text { vazio \% } \\
\end{array}$ & Qualidade* \\
\hline Data de Nascimento & Obrigatório & 99 & 1 & \multirow{2}{*}{$\begin{array}{l}\text { Excelente (não } \\
\text { completude menor } \\
\text { de } 5 \% \text { ) }\end{array}$} \\
\hline Nome da mãe & Essencial & 96,6 & 3,4 & \\
\hline Zona & Essencial & 94,8 & 5,2 & \multirow{5}{*}{$\begin{array}{l}\text { Bom (não completude } \\
\text { de } 5 \% \text { a } 10 \% \text { ) }\end{array}$} \\
\hline Data do Encerramento & Essencial & 94,1 & 5,9 & \\
\hline Data da Investigação & Obrigatório & 94 & 6 & \\
\hline Nome do Bairro & Essencial & 93 & 7 & \\
\hline Gestante & Obrigatório & 92,7 & 7,3 & \\
\hline Classificação Final & Obrigatório & 89,2 & 10,8 & \multirow{10}{*}{$\begin{array}{l}\text { Regular (não } \\
\text { completude de } 10 \% \\
\text { a } 20 \% \text { ) }\end{array}$} \\
\hline Resultado do Isolamento Viral & Essencial & 89,1 & 10,9 & \\
\hline Número do Telefone & Essencial & 89 & 11 & \\
\hline Critério de Confirmação/Descarte & Obrigatório & 88,4 & 11,6 & \\
\hline Resultado do Exame RT-PCR & Essencial & 88,1 & 11,9 & \\
\hline Resultado da Histopatologia & Essencial & 88,1 & 11,9 & \\
\hline Resultado da Imunohistoquímica & Essencial & 87,3 & 12,7 & \\
\hline Resultado do Exame Sorológico - IgM & Essencial & 86,7 & 13,3 & \\
\hline Raça/Cor & Essencial & 83,8 & 16,2 & \\
\hline Evolução do Caso & Essencial & 80,8 & 19,2 & \\
\hline Escolaridade & Essencial & 51 & 49 & $\begin{array}{l}\text { Ruim (não completude } \\
\text { de } 20 \% \text { a } 50 \% \text { ) }\end{array}$ \\
\hline Número do Cartão SUS & Essencial & 37,1 & 62,9 & \multirow{6}{*}{$\begin{array}{l}\text { Muito Ruim (não } \\
\text { completude de 50\% } \\
\text { ou mais) }\end{array}$} \\
\hline Ocorreu Hospitalização? & Essencial & 32,2 & 67,8 & \\
\hline $\begin{array}{l}\text { O caso é Autóctone do Município de } \\
\text { Residência? }\end{array}$ & $\begin{array}{l}\text { Obrigatório, } \\
\text { se confirmado }\end{array}$ & 21,3 & 78,7 & \\
\hline $\begin{array}{l}\text { Município (Provável da Fonte de } \\
\text { Infecção) }\end{array}$ & Essencial & 17,3 & 82,7 & \\
\hline $\begin{array}{l}\text { Ocupação/Ramo de Atividade } \\
\text { Econômica }\end{array}$ & Essencial & 16,9 & 83,1 & \\
\hline Sorotipo & Obrigatório & 1,3 & 98,7 & \\
\hline
\end{tabular}

Em relação à qualidade dos campos essenciais, observou-se uma variabilidade nos escores, com classificações de muito ruim à excelente, sendo um predomínio de completude regular $(47,1 \%, \mathrm{n}$ $=8)$, seguido de muito ruim $(23,5 \%, \mathrm{n}=4)$, bom
$(17,6 \%, \mathrm{n}=3)$, excelente $(5,9 \%, \mathrm{n}=1)$ e ruim $(5,9 \%, n=1)$. Dentre os campos essenciais do bloco de Dados Individuais, as variáveis número de telefone e raça/cor apresentaram completudes regulares, tendo respectivamente $11 \%$ e $16,2 \%$ e 
a variável escolaridade foi a única a ser classificada como completude ruim, com $49 \%$ de informações ignoradas ou vazias. Quanto aos campos essenciais do bloco de Dados Laboratoriais da ficha, $100 \%$ (5) apresentaram classificação regular, com não completude entre $10 \%$ e $20 \%$. Classificaram-se com qualidade muito ruim as variáveis essenciais número do cartão do SUS $(62,9 \%)$ e ocupação/ramo de atividade econômica $(83,1 \%)$, pertencentes aos Dados Individuais do paciente na ficha de notificação e as variáveis se ocorreu hospitalização $(67,8 \%)$ e município com provável fonte de infecção (82,7\%), pertencentes aos Dados da Conclusão na ficha de investigação de dengue (Tabela 2).

A variável nome da mãe foi classificada com excelente, apresentando 3,4\% de informações ignoradas ou vazias e as variáveis nome do bairro e zona tiveram classificação boa, com não completude de $7 \%$ e $5,2 \%$, respectivamente (Tabela 2). Cabe ressaltar que todos os campos analisados não sofreram mudanças em suas classificações durante os anos estudados.

Ao se observar a variação da não completude (Tabela 3), nota-se que as variáveis número do cartão do SUS ( $\mathrm{rs}=-0,8 ; \mathrm{p}=0,005)$, resultado do exame sorológico $-\operatorname{IgM}(\mathrm{rs}=-0,7 ; \mathrm{p}=0,023)$, data de encerramento ( $\mathrm{rs}=-0,8 ; \mathrm{p}=0,006)$, evolução do caso ( $\mathrm{rs}=-0,7 ; \mathrm{p}=0,035)$ e se ocorreu hospitalização ( $\mathrm{rs}=-0,9 ; \mathrm{p}=0,001)$ foram decrescentes e estatisticamente significantes ao longo dos anos. Dentre as variáveis que apresentaram correlação positiva da não completude, nenhuma apresentou significância estatística.

\section{Discussão}

O interesse sobre a avaliação da qualidade da informação em saúde vem ganhando cada vez mais evidência no Brasil. Dados com qualidade são essenciais para o planejamento e gestão de recursos, para a fundamentação de decisões das ações de controle da doença, bem como para a promoção e proteção da saúde da população ${ }^{17,18}$.

Evidenciou-se que a proporção de informação ignorada (preenchimento com código específico de ignorado) e de informações em branco foi elevada para a maioria das variáveis da ficha de dengue, referentes às notificações do município de Fundão-ES, no período de 2007 a 2015, com exceção dos campos-chave e de algumas variáveis obrigatórias.

Embora haja a premissa de preenchimento total para os campos obrigatórios, observou-se
Tabela 3. Correlação entre a não completude e o ano de notificação de dengue no SINAN. Fundão, Espírito Santo, 2007-2015.

\begin{tabular}{|c|c|c|}
\hline Variável & $\mathbf{R}$ & p-valor \\
\hline \multicolumn{3}{|l|}{ Dados Individuais } \\
\hline Data de Nascimento & $-0,5$ & 0,139 \\
\hline Nome da mãe & 0,4 & 0,355 \\
\hline Gestante & 0,0 & 0,966 \\
\hline Raça/Cor & 0,2 & 0,650 \\
\hline Escolaridade & 0,1 & 0,763 \\
\hline $\begin{array}{l}\text { Ocupação/Ramo de Atividade } \\
\text { Econômica }\end{array}$ & 0,4 & 0,354 \\
\hline Número do Cartão SUS & $-0,8$ & 0,005 \\
\hline \multicolumn{3}{|l|}{ Dados de Residência } \\
\hline Número do Telefone & $-0,5$ & 0,213 \\
\hline Nome do Bairro & $-0,2$ & 0,606 \\
\hline Zona & $-0,4$ & 0,306 \\
\hline \multicolumn{3}{|l|}{ Dados Laboratoriais } \\
\hline $\begin{array}{l}\text { Resultado do Exame } \\
\text { Sorológico - IgM }\end{array}$ & $-0,7$ & 0,023 \\
\hline Resultado do Isolamento Viral & $-0,7$ & 0,057 \\
\hline Resultado do Exame RT-PCR & $-0,6$ & 0,088 \\
\hline Sorotipo & 0,3 & 0,371 \\
\hline Resultado da Histopatologia & $-0,6$ & 0,099 \\
\hline $\begin{array}{l}\text { Resultado da } \\
\text { Imunohistoquímica }\end{array}$ & $-0,6$ & 0,099 \\
\hline \multicolumn{3}{|l|}{ Dados da Conclusão } \\
\hline Classificação Final & $-0,5$ & 0,154 \\
\hline $\begin{array}{l}\text { Critério de Confirmação/ } \\
\text { Descarte }\end{array}$ & $-0,6$ & 0,067 \\
\hline $\begin{array}{l}\text { Município (Provável da Fonte } \\
\text { de Infecção) }\end{array}$ & 0,1 & 0,831 \\
\hline $\begin{array}{l}\text { O caso é Autóctone do } \\
\text { Município de Residência? }\end{array}$ & 0,1 & 0,828 \\
\hline Data do Encerramento & $-0,8$ & 0,006 \\
\hline Data da Investigação & $-0,6$ & 0,104 \\
\hline Evolução do Caso & $-0,7$ & 0,035 \\
\hline Ocorreu Hospitalização? & $-0,9$ & 0,001 \\
\hline
\end{tabular}

que alguns deles ocorreram preenchimento abaixo de $100 \%$ (Tabela 2). A não completude do campo obrigatório data de nascimento na ficha de notificação de dengue dá-se pelo fato de existir a opção para preenchimento do campo idade ou data de nascimento.

No campo gestante, a incompletude aconteceu pelo fato de que na ficha existe a opção "ignorado" (dígito 9). A não completude dos campos data de investigação, classificação final do caso, critério de confirmação/descarte, caso autóctone do município de residência e sorotipo pode ter ocorrido pelo fato desses campos fazerem parte das 
fichas de investigação de dengue, onde alguns dados são preenchidos posteriormente à inserção da notificação no SINAN, durante a investigação e encerramento do caso. Porém, por serem dados obrigatórios de investigação e encerramento dos casos, possuem grande importância epidemiológica e a ausência desses dados impossibilita a identificação da real análise da situação do agravo no município.

Segundo Ferreira et al. ${ }^{19}$, a identificação e a correção de inconsistências dos dados nos sistemas de informação são importantes para maior confiabilidade das informações, melhorando assim a fidelidade dos indicadores e a otimização do planejamento das ações voltadas à saúde da população.

As fichas de notificação e investigação do SINAN apresentam um quantitativo expressivo de campos. No entanto, apesar da orientação de que todos os campos devam ser preenchidos, os mecanismos do sistema que reforçam essa obrigatoriedade atingem apenas alguns deles ${ }^{20}$. A maioria das variáveis são campos essenciais, ou seja, o seu preenchimento, apesar de importante para cálculos de indicadores epidemiológicos, não é obrigatório para a inserção da notificação no sistema ${ }^{15,21}$.

A variável nome da mãe, que tem grande importância para a identificação do paciente, foi a única variável essencial a ser classificada com completude excelente. As variáveis essenciais zona e nome do bairro, que são fundamentais para realização de estudos ecológicos e ações da vigilância epidemiológica juntamente com a vigilância ambiental para controle do Aedes aegyp$t i$, foram classificadas com boa completude dos dados.

Os resultados desse estudo demonstraram que todas as variáveis essenciais relacionadas aos Dados Laboratoriais (resultado do isolamento viral, resultado do exame RT-PCR, resultado da histopatologia, resultado da imunohistoquímica e resultado do exame sorológico - IgM), tiveram completude regular, com ausência de 10 a 20\% dos dados.

O diagnóstico laboratorial da dengue é realizado pela identificação de componentes virais ou de anticorpos, e a indicação do método a ser utilizado depende do tempo decorrido desde o início dos sintomas ${ }^{1}$. O isolamento viral é considerado o padrão-ouro no diagnóstico, sendo indicado, preferencialmente, até o quinto dia da doença, no período de viremia ${ }^{22}$.

Quanto à sorologia, que é o método de escotha de confirmação laboratorial na rotina, o re- sultado depende da detecção de anticorpos específicos da classe IgM, com período de realização recomendado após o sexto dia dos sintomas ${ }^{1,22}$. Para que se tenha a informação se o exame foi ou não realizado, é importante que os campos referentes aos dados de diagnósticos laboratoriais sejam preenchidos. Quando esses campos se encontram em branco, não há como saber se o exame não foi solicitado para o paciente ou se foi realizado, não houve preenchimento do resul$\operatorname{tado}^{23}$.

Alguns campos relevantes para a análise da situação da dengue apresentaram preenchimento insatisfatório, o que enseja repensar mecanismos mais efetivos para a melhoria da completude. O mesmo é encontrado em outros estudos, inclusive de agravos distintos de notificação compulsória. Segundo Alvares et al. ${ }^{24}$, mudanças na padronização do sistema operacional, como uma reclassificação de campos "essenciais" em "obrigatórios", poderiam melhorar os índices de preenchimento dos campos.

Observou-se com o estudo, que o campo raça/cor foi classificado como completude regular e a variável escolaridade foi a única a ser classificada com completude ruim, tendo ausência de $49 \%$ dos dados. Esses achados corroboram a literatura, apresentando preenchimentos insuficientes dessas variáveis em muitos Sistemas de Informação em Saúde (SIS) nacionais, bem como a variável número do cartão do SUS. Um estudo realizado em Juiz de Fora, no ano de 2010, com análise de completude das fichas de dengue, também evidenciou ausência de dados nas mesmas variáveis ${ }^{23}$. A completude regular para a variável raça/cor deve-se, provavelmente, ao fato de a classificação dos indivíduos segundo cor ainda ser considerada bastante subjetiva ${ }^{23}$. Conforme evidências similares da não completude da variável raça/cor em seus estudos, Braz et al. ${ }^{25}$ recomendam o monitoramento permanente do preenchimento das variáveis, com proposta de capacitação para os responsáveis pela coleta e alimentação dos dados, viabilizando a possibilidade de uma adequada avaliação dos sistemas de informação em saúde para o recorte étnico-racial.

Como classificação de completude muito ruim, destaca-se a falta de informações se houve hospitalização ou não do paciente, se o caso é autóctone do município de residência e o provável município de infecção. Para as duas últimas variáveis, consideram-se incompletudes justificáveis, visto que estas só são preenchidas em caso de confirmação da dengue, por critério clínico-epidemiológico ou por critério laboratorial. A vari- 
ável sorotipo, que obteve ausência de 98,7\% dos dados, é uma variável obrigatória quando os exames de isolamento viral ou PCR forem positivos. Sua completude diretamente ligada à realização e ao resultado de tais exames e a falta da identificação ou do registro da mesma no sistema pode dificultar o entendimento do comportamento epidêmico do vírus circulante no município. Essa ausência de dados impossibilita estimar os riscos populacionais e futuras epidemias, limitando a capacidade dos serviços de saúde em responder e se prepararem para futuras emergências de saúde pública, relacionadas ao agravo ${ }^{22}$.

As falhas na completude e consequentemente na análise e processamento dos dados, além de implicarem uma estimativa equivocada da magnitude do surto ou epidemia, tanto de dengue como de outras doenças de notificação compulsória, acarretam uma dificuldade de ações e recursos para o seu enfrentamento, com impedimentos de tomadas de decisão em tempo hábil a fim de reduzir o avanço de disseminação e de infecção da doença ${ }^{26}$. É preciso reconhecer que o uso dos SIS no Brasil vem melhorando significativamente, porém, seu aprimoramento constitui-se num processo contínuo de avaliações e ajustes $^{27}$.

De acordo com Assis et al. ${ }^{23}$, o significativo número de variáveis com completudes classificadas como regulares, ruins e muito ruins dá-se em consequência da falta de motivação ou tempo suficiente para o completo preenchimento das fichas, diante da priorização das demais demandas nos serviços de saúde. Outra explicação é a consideração feita pela maioria dos profissionais de saúde de que o preenchimento dos instrumentos de coleta de dados é uma atividade meramente burocrática e de importância secundária ${ }^{17}$.

Embora seja possível a replicação dos métodos utilizados nesse estudo para avaliação dos dados em qualquer município do país, características regionais e peculiares aos serviços de saúde do município devem ser levadas em consideração, principalmente por Fundão se tratar de um município de pequeno porte, com características interioranas, de poucos recursos financeiros e reduzidas equipes de saúde. A propósito dessa observação, Muguande et al. ${ }^{28}$ consideram que o grau de completude dos dados de notificação em SIS sofrem influência dos recursos e prioridades dos gestores de saúde e, especialmente, daqueles responsáveis pela vigilância em saúde pública.

As arboviroses, em especial a dengue, são consideradas um crescente problema de saúde pública, devido tanto a sua grande dispersão mundialmente como pela adaptação do Aedes nas mais diversas localidades, como no Brasil. Desta forma, torna-se necessário políticas com amplo espectro que envolvam diversos setores da sociedade, envolvendo tanto questões de saúde como ambientais e de urbanização ${ }^{29}$. Neste contexto, a notificação compulsória, tanto para a dengue quanto para as demais doenças, é ferramenta fundamental para subsidiar intervenções.

A literatura aponta que a alteração da versão Sinan-Windows para Sinan-Net influenciou positivamente quanto a inserção de dados no sistema operacional das notificações de dengue, entretanto, tal fato não gerou mudanças consideráveis na completude dos dados ${ }^{30}$. A qualidade de suas informações é condição essencial para o conhecimento do real perfil epidemiológico e para a análise da situação de saúde, subsidiando consequentemente, as tomadas de decisão para o controle do agravo, tanto a nível municipal, estadual, quanto federal. Além disso, a qualidade dos dados inseridos nos Sistemas de Informação é importante não apenas para o planejamento das ações de saúde, mas também pelo investimento contínuo do Ministério da Saúde em garantir sua operacionalização. Todo o esforço e o custo são perdidos quando o profissional deixa de fornecer as informações corretas e completas nos formulários padronizados que devem ser preenchidos.

Como limitação do estudo, destaca-se o fato do município pesquisado ser classificado como de pequeno porte, desta maneira, não se pode extrapolar os achados para nível nacional nem para municípios de médio e grande porte.

\section{Conclusão}

Frente a não completude dos campos das fichas de notificações de dengue no município de Fundão-ES, constatou-se que a qualidade dos dados foi, em sua maioria, classificada como regular e muito ruim entre os anos de 2007 a 2015. Desse modo, evidenciou-se que a falta de importantes informações contribui para o não conhecimento do real perfil epidemiológico dos casos de dengue no município e consequentemente, a dificuldade de avaliação da situação do agravo e das tomadas de decisões para controle, através do banco de dados do SINAN. Desta forma, é necessária a busca para uma construção de registro de dados consistentes e fidedignos, uma vez que eles poderão subsidiar políticas públicas institucionais.

Torna-se, portanto, imprescindível o estabelecimento de estratégias no processo de capaci- 
tação das equipes de saúde e dos gestores municipais, para a sensibilização e conscientização da importância da qualidade do registro das notificações compulsórias, não somente da dengue, mas dos demais agravos, doenças e eventos de saúde pública, de modo que possam fundamentar os sistemas de informação em saúde e viabilizar uma efetiva vigilância epidemiológica local.

\section{Colaboradores}

CA Marques participou da análise e interpretação dos dados e redação do artigo. MM Siqueira participou da concepção e delineamento do estudo e da revisão crítica do artigo. FB Portugal participou da concepção e delineamento do estudo, da análise e interpretação dos dados, da redação do artigo e da revisão crítica do mesmo.

\section{Agradecimentos}

À Secretaria Municipal de Saúde do Município de Fundão-ES, em especial a Vigilância Epidemiológica, pela cessão dos dados para a realização desse estudo. 


\section{Referências}

1. Brasil. Ministério da Saúde (MS). Secretaria de Vigilância em Saúde. Coordenação Geral de Desenvolvimento da Epidemiologia em Serviços. Guia de Vigilância em Saúde. Volume Único. Brasília: MS; 2016.

2. Brasil. Ministério da Saúde (MS). Secretaria de Vigilância em Saúde. Departamento de Vigilância Epidemiológica. Guia de Vigilância Epidemiológica. 7a ed. Brasília: MS; 2009.

3. Ribeiro AF, Marques GRAM, Voltolini JCV, Condino MLF. Associação entre incidência de dengue e variáveis climáticas. Rev Saude Publica 2006; 40(4):671676.

4. Brasil. Ministério da Saúde (MS). Secretaria de Vigilância em Saúde. Monitoramento dos casos de dengue, febre de chikungunya e febre pelo vírus Zika até a Semana Epidemiológica 10, 2017. Boletim Epidemiológico 2017; 48(09):1-10.

5. Brasil. Ministério da Saúde (MS). Secretaria de Vigilância em Saúde. Departamento de Vigilância das Doenças Transmissíveis. Plano de Contingência Nacional para Epidemias de Dengue. Brasília: MS; 2015.

6. Ferreira GLC. Global dengue epidemiology trends. Rev Inst Med Trop São Paulo 2012; 54(18):5-6.

7. Barreto ML, Teixeira MG. Dengue no Brasil: situação epidemiológica e contribuições para uma agenda de pesquisa. Estud Av 2008; 22(64):53-72.

8. Paes NA, Albuquerque MEE. Avaliação da qualidade dos dados populacionais e cobertura dos registros de óbitos para as regiões brasileiras. Rev Saude Publica 1999; 33(1):33-43.

9. Pereira MG. Vigilância epidemiológica. In: Pereira MG. Epidemiologia: Teoria e Prática. Rio de Janeiro: Editora Guanabara Koogan S.A.; 2000. p. 449-482.

10. Laguardia J, Domingues CMA, Carvalho C, Lauermam CR, Macário E, Glatt R. Sistema de informação de agravos de notificação (Sinan): desafios no desenvolvimento de um sistema de informação em saúde. Epidemiol Serv Saude 2004; 13(3):135-146.

11. Souza ER, Njaine K, Minayo MCS. Qualidade da informação sobre violência: um caminho para a construção da cidadania. Cadernos do Programa de Pós-graduação em Ciências da Informação 1996; 2(1):104-112.

12. Glatt R. Análise da qualidade da base de dados de Aids do sistema de informação de agravos de notificação (Sinan) [dissertação]. Rio de Janeiro: Escola Nacional de Saúde Pública; 2005.

13. Prefeitura Municipal de Fundão [página na Internet]. [acessado 2017 Jun 7]. Disponível em: http://www. fundao.es.gov.br

14. Instituto Brasileiro de Geografia e Estatística (IBGE). Espírito Santo, Fundão. População Estimada em 2016 [página na Internet]. 2016 [acessado 2017 Jun 8]. Disponível em: http://cidades.ibge.gov.br/xtras/perfil. php?codmun $=320220$

15. Brasil. Ministério da Saúde (MS). Secretaria de Vigilância em Saúde. Departamento de Vigilância Epidemiológica. Coordenação Geral de Doenças Transmissíveis. Gerência Técnica do Sinan. Roteiro para uso do Sinan net, análise de base de dados e cálculo de indicadores epidemiológicos e operacionais. Brasília: MS; 2008.
16. Romero DE, Cunha CB. Avaliação da qualidade das variáveis sócio-econômicas e demográficas dos óbitos de crianças menores de um ano registrados no Sistema de Informações sobre Mortalidade do Brasil (1996/2001). Cad Saude Publica 2006; 22(3):673-684.

17. Oliveira MEP, Soares MRAL, Costa MCN, Mota ELA Avaliação da completitude dos registros de febre tifoide notificados no SINAN pela Bahia. Epidemiol Serv Saúde 2009; 18(3):219-226.

18. Toledo ALA, Escosteguy CC, Medronho RA, Andrade FC. Confiabilidade do diagnóstico final de dengue na epidemia 2001-2002 no município do Rio de Janeiro, Brasil. Cad Saude Publica 2006; 22(5):933-940.

19. Ferreira JSA, Vilela MBR, Aragão PS, Oliveira RA, Tiné RF. Avaliação da qualidade da informação: linka$g e$ entre SIM e SINASC em Jaboatão dos Guararapes (PE). Cien Saude Colet 2011; 16(1):1241-1246.

20. Santos ED, Garret DO. Avaliação do Sistema de Vigilância de Hantavírus no Brasil. Epidemiol Serv Saude 2005; 14(1):15-31.

21. Brasil. Ministério da Saúde (MS). Secretaria de Vigilância em Saúde. Departamento de Vigilância Epidemiológica. Sistema de Informação de Agravos de Notificação - Sinan: normas e rotinas. $2^{\mathrm{a}}$ ed. Brasília: Editora do Ministério da Saúde; 2007.

22. Brasil. Ministério da Saúde (MS). Secretaria de Vigilância em Saúde. Departamento de Vigilância Epidemiológica. Diretrizes nacionais para a prevenção e controle de epidemias de dengue. Brasília: MS; 2009.

23. Assis VC, Amaral MPH, Mendonça AE. Análise da qualidade das notificações de dengue informadas no sistema de informação de agravos de notificação, na epidemia de 2010, em uma cidade pólo da zona da mata do Estado de Minas Gerais. Rev APS 2015; 17(4):429-437.

24. Alvares JK, Pinheiro TMM, Santos AF, Oliveira GL. Evaluation of the completeness of compulsory work -related notifications recorded by county industrial center in Brazil, 2007 - 2011. Rev Bras Epidemiol 2015; 18(1):123-136

25. Braz RM, Oliveira PTR, Reis AT, Machado NMS. Avaliação da completude da variável raça/cor nos sistemas nacionais de informação em saúde para aferição da equidade étnico-racial em indicadores usados pelo Índice de Desempenho do Sistema Único de Saúde. Saude Debate 2013; 37(99):554-562.

26. Cerqueira ACB, Miranda AEB, Maciel ELN. Completude do banco de dados de gestante HIV positivo e de AIDS em menores de treze anos do sistema de informação de agravos de notificação: Vitória, 2000 a 2006. Cad Saude Colet 2010; 18(1):191-194.

27. Jorge MHPM, Laurenti R, Gotlieb SLD. Avaliação dos sistemas de informação em saúde no Brasil. Cad Saude Colet 2010; 18(1):7-18.

28. Muguande OF, Ferraz ML, França E, Gontijo ED. Avaliação da qualidade do Sistema de Vigilância Epidemiológica de doença de chagas aguda em Minas Gerais, 2005-2008. Epidemiol Serv Saude 2011; 20(3):317-325. 
29. Donalisio MR, Freitas André RR, Zuben APBV. Arboviruses emerging in Brazil: challenges for clinic and implications for public health. Rev Saude Publica 2017; 51:30.

30. Barbosa JR, Barrado JCS, Zara ALSA, Siqueira JJB. Avaliação da qualidade dos dados, valor preditivo positivo, oportunidade e representatividade do sistema de vigilância epidemiológica da dengue no Brasil, 2005 a 2009. Epidemiol Serv Saude 2015; 24(1):49-58.

Artigo apresentado em 01/02/2018

Aprovado em 30/07/2018

Versão final apresentada em 01/07/2018 